David Lagmanovich

\title{
CONTIGUIDAD DE LOS PARQUES, CONTINUIDAD DE LA ESCRITURA
}

\author{
a E. Dale Carter, Jr.
}

El primero de los relatos incluidos por Julio Cortázar en su tercer libro de cuentos, Final del juego (1964) (1), que pasa luego --en otro orden-- a la sección "Juegos" de su recopilación Relatos (1970) (2), es "Continuidad de los parques".

En el título del volumen tanto como en el de la sección aparece, como categoría superior a la cual se referiría la construcción narrativa que nos ocupa, la palabra "juego". El examen crítico se siente, pues, forzado a examinar este punto :--encaminado por el autor, diríase, hacia este punto-- , ya explorado por Jaime Alazraki en su estudio "Homo sapiens vs. homo ludens en tres cuentos de Cortázar" (3): nos interesa saber cuáles son las características de este juego, de qué manera se manifiesta lo lúdico; cómo se articula tal actitud con la "literaturización" que de inmediato aparece como uno de sus más caracterîsticos rasgos distintivos (4); sobre todo, quizá, nos interesa averiguar cómo la "continuidad de los parques" que se menciona en el título --condición eminentemente temática-- se transfigura en una condición textual, en una verdadera "continuidad de la escritura".

La composición, sin llegar a ser un "microcuento", es notablemente breve: dos largos párrafos que, en la edición original, alcanzan respectivamente 40 y 17 líneas de tipografia; medida de otra manera, algo más de 540 palabras. Volveremos sobre esta distribución del material en dos părrafos de extensión disimil, pues el hecho constituye uno de los indicios estructurales más interesantes del cuento. Pero ante todo, la ya apuntada brevedad nos permite transcribir --operación no frecuente-la totalidad del texto: 
Habia empezado a leer la novela unos días antes. La abandonб por negocios urgentes, volvió a abrirla cuando regresaba en tren a la finca; se dejaba interesar lentamente por la trama, por el dibujo de los personajes. Esa tarde, 5 después de escribir una carta a su apoderado y discutir con el mayordomo una cuestión de aparcerías, volvió al libro en la tranquilidad del estudio que miraba hacia el parque de los robles. Arrellanado en su sillón favorito, de espaldas a la puerta que lo hubiera molestado como una

10 irritante posibilidad de intrusiones, dejó que su mano $1 z$ quierda acariciara una y otra vez el terciopelo verde y se puso a leer los últimos capítulos. Su memoria retenía sin esfuerzo los nombres y las imágenes de los protagonistas; la ilusión novelesca lo ganó casi en seguida. Gozaba del

15 placer casi perverso de irse desgajando línea a línea de lo que lo rodeaba, y sentir a la vez que su cabeza descansaba cómodamente en el terciopelo del alto respaldo, que los cigarrillos seguían al alcance de la mano, que más allá de los ventanales danzaba el aire del atardecer bajo los

20 robles. Palabra a palabra, absorbido por la sórdida disyuntiva de los héroes, dejándose ir hacia las imágenes que se concertaban y adquirían color y movimiento, fue testigo del último encuentro en la cabaña del monte. Primero entraba la mujer, recelosa; ahora llegaba el amante, las-

25 timada la cara por el chicotazo de una rama. Admirablemente restañaba ella la sangre con sus besos, pero él rechazaba las caricias, no había venido para repetir las ceremonias de una pasión secreta, protegida por un mundo de hojas secas y senderos furtivos. El puñal se entibiaba

30 contra su pecho, y debajo latía la libertad agazapada. Un diálogo anhelante corría por las páginas como un arroyo de serpientes, y se sentía que todo estaba decidido desde siempre. Hasta esas caricias que enredaban el cuerpo del amante como queriendo retenerlo y disuadirlo, dibujaban

35 abominablemente la figura de otro cuerpo que era necesario destruir. Nada había sido olvidado: coartadas, azares, posibles errores. A partir de esa hora cada instante tenía su empleo minuciosamente atribuido. El doble repaso despiadado se interrumpía apenas para que una mano acariciara una mejilla. Empezaba a anochecer.

Sin mirarse ya, atados rígidamente a la tarea que los esperaba, se separaron en la puerta de la cabaña. Ella debía seguir por la senda que iba al norte. Desde la senda 
opuesta êl se volvió un instante para verla correr con el 45 pelo suelto. Corrió a su vez, parapetándose en los árboles y los setos, hasta distinguir en la bruma malva del crepasculo la alameda que llevaba a la casa. Los perros no debtan ladrar, y no ladraron. E.l mayordomo no estaría a esa hora, y no estaba. Subió los tres peldaños del porche y entró.

50 Desde la sangre galopando en sus oídos le llegaban las palabras de la mujer primero una sala azul, después una galería, una escalera alfombrada. En lo alto, dos puertas. Nadie en la primera habitación, nadie en la segunda. La puerta del salón, y entonces el puñal en la mano, la luz de los 55 ventanales, el alto respaldo de un sillón de terciopelo verde, la cabeza del hombre en el sillón leyendo una novela.

Lo primero que, en mı opinión, resalta en esta ceñida construcción narrativa es -como lo he indicado sucintamente en otro trabajo (5) - - lo avanzado del proceso de "literaturizacion" que aquí se realiza: algo similar a lo que percibe Alazraki en su último libro cuando, al estudiar la voz narrativa en la ficción breve de Cortázar, señala que la estrategia que usa el escritor respecto al narrador en tercera persona "resulta en una voz narrativa que habla con el mismo tono y timbre que las voces de los personajes" y que esta voz es "enigmáticamente literaria" en el cuento que consideramos (6). Claro que sí: por cierto que la voz narrativa, y todo lo demás del cuento, pueden caracterizarse como "enigmáticamente literarios"; como lo expresé en el trabajo al que acabo de hacer referencia, cuando se manifiesta con valencia positiva el rasgo distintivo que llamo "literaturización", la narración resulrante está centrada en la estructura del contar o, dicho de otra forma, la eficacia del cuento depende casi exclusivamente de la modalidad de su entrega al lector, de su forma de presentación/penetración. Cuál es esa forma, cómo operan los procesos que llevan a la configuración de un típico relato breve cortazariano, es lo que corresponde seguir explorando en estas páginas.

No deseamos dejar de mencionar que --como también lo apunté en mi trabajo de 1972 , sin poder desarrollarlo en aquella oportunidad (7)-- el cuento bajo examen se caracteriza asimismo por la presencia de otro rasgo, que es el de la "enmarcación". La asignación de valor positivo a este rasgo implica que "la obra literaria crea un marco estructural dentro del cual se desarrolla otra obra literaria"; como entonces dije, ejemplificando el procedimiento precisamente con el mismo cuento,

la acción de este cuento incluye la lectura de una novela en donde se relata, precisamente, la acción que se está 
desarrollando; $o$, si se prefiere, donde dos de los protagonistas imaginan al tercero leyendo una novela que, no obstante, los incluye e incluye sus acciones.

Vale decir que, en cierta forma, asistimos también a un "pasaje" -otra palabra predilecta de Cortázar(8)-- o transformación, ya sea que los personajes de la novela leída por el protagonista salgan de las páginas del libro y se dirijan contra él, ya sea que él mismo se proyecte o introduzca dentro del libro y pase a ser, no sólo el personaje del cuento de Cortázar, sino uno más dentro de la novela leída, es decir, un personaje de una ficción segunda. La "continuidad" que menciona el título se verifica sin duda entre estos dos planos igualmente ficticios, aunque uno más abstracto y remoto que el otro: la "continuidad" es lo que permite que uno sea ganado por "la ilusion novelesca" mencionada por la voz narrativa. La operación real sería un acto de magia; en la operación ficticia, el libro funciona claramente como un "libro mágico", según un código que tiene ilustres antecedentes y, en Jorge Luis Borges, uno de sus máximos cultores (9).

Ahora bien: la "magia" de la literatura es una magia imperfecta, puesto que no cambia las sustancias del mundo sino solamente altera sus imágenes, merced a la utilización de un número finito de elementos. En "Continuidad de los parques", tal operación presuntamente mágica se lleva a cabo mediante la hábil combinación de un reducido número de procedimientos, de los cuales --por más demostrables-- seleccionamos tres, a saber: 1) el uso de un subtexto literario; 2) las estrategias del léxico, y sobre todo, 3) la estructuración del relato no sólo según las fases de la acción, sino principalmente en têrminos de la estructura profunda manifestada por las configuraciones de tiempos verbales reveladas en el texto. Haremos un rápido repaso de lo que sugiere cada uno de estos enfoques.

1. El subtexto literario. "Continuidad de los parques" representa el término de un proceso de "literaturización", entre otras causas, porque se apoya en un subtexto literario: en Lady Chatterley's Lover ("El amante de Lady Chatterley"), de D. H. Lawrence (10). La ambientación procede de allí (o, en todo caso, de alguna otra novela inglesa similar, de alguna narración que comparta su tiṕología): el "romance" de Lawrence maneja la misma oposición entre "el parque" y "el bosque"; los amantes --Connie y Mellors-- se encuentran en una cabaña del bosque; no es extraño (como en el cap. $X$ ) que él se quede observándola mientras ella sale corriendo, al atardecer; en la casa, casi siempre inmóvil, está Clifford, dueño de ese ámbito cerrado en- 
marcado por un macizo de robles... Son demasiados datos para suponer que se trata de una mera coincidencia; por el contrario, es coino si Cortázar huhiera tomado la novela inğglesa como "obra abierta" y la hubiera continuado, a partir de cierto punto --deconstruyéndola-- en una dirección inesperada. Y el resultado de esta relectura es también sorprendente para nosotros; porque los parques cuya continuidad percibimos son, ahora, el parque del cuento de Cortázar y el de la novela del escritor inglés.

2. Las estrategias del léxico. El manejo de los elementos léxicos con que se construye el relato está signado por una doble estrategia: la instauración de la ambigüedad y la búsqueda de la circularidad.

Lo primero se manifiesta sobre todo al principio del relato. El hombre regresa en tren a "la finca", palabra absolutamente neutra que puede designar desde un lote de terreno relativamente espacioso hasta un completo establecimiento rural; discute con el "mayordomo" (que al principio se escucha como un supervisor del trabajo agrícola, un "capataz", pero puede reelerse más tarde como un sirviente principal de la casa, un "butler") una cuestión de "aparcerías", palabra técnica del uso legal, pero de impreciso valor en el habla corriente. En la novela que el hombre lee, los amantes se encuentran "en la cabaña del monte": "cabaña" es el término preciso dentro del juego contextual que estamos explorando, pero "monte" (en lugar de "bosque", mucho más específicol introduce una curiosa --y seguramente voluntaria-- deformación. Es que, en el momento del ingreso del lector en este cuento ("al entrar en este parque") no debemos reconocer el ambiente verdadero: sólo en la fusión de la narración primera y la narración segunda hemos de llegar a percibir la existencia de un solo y único espacio, el de ese continuum o continuidad instaurada por el hecho mismo del narrar.

Junto a esa ambigüedad del espacio, que anticipa la ambigüedad de la totalidad del relato, y que se consigue fácilmente mediante el manejo de unos cuantos elementos léxicos, hay otro uso de las palabras que llama la atención: la repetición simétrica para sugerir --subliminalmente, podría decirse-- la recurrencia o circularidad. Determinadas palabras --claves, aunque él no lo sepa, para el narratario-- se repiten espejísticamente; siempre lo hacen en uno y otro de los dos párrafos que constituyen el cuento, y siempre establecen un movimiento como de dentro a fuera.

Para identificar estas recurrencias será conveniente mencionar las líneas del texto en que se producen, teniendo en cuenta que el primer párrafo --la prótasis, en la sintaxis narrativa, 
de esta oración que es el cuento-- se extiende de la línea 1 a la 40, y el segundo - la apódosis-- abarca las líneas 41 a 57. $\mathrm{Si}$ lo que trato de mostrar es correcto, una mención hacia el final del primer párrafo se corresponderá con otra a principios del segundo; una en medio del primero encontrará su equivalente en medio del segundo; y finalmente, hacia afuera, una palabra o expresión a comienzos del primer párrafo hará "pendant" con una que, situada al final del segundo párrafo, parece desempeñar una función similar. Veremos que esto es precisamente lo que ocurre.

$Y$ así, en efecto, a "el puñal se entibiaba contra su pecho" (línea 29) corresponde "entonces el puñal en la mano" (1. 54); "el altimo encuentro en la cabaña del monte" (1.24) es reproducido en forma invertida mediante "se separaron en la puerta de la cabaña" (uno de los varios ordenamientos verbales que sugieren el quiasmo, 1. 42); "el terciopelo del alto respaldo" (1. 17) va frente a "el alto respaldo de un sillón de terciopelo verde" (11. 55-56); "sillón" (1. 8) encuentra eco en "sillón" (1. 56), como "mayordomo" (1.6) en "mayordomo" (1. 48); y, por último, la frase con infinitivo, "leer la novela", de la primera línea del cuento, se reencuentra en la frase con gerundio --otra forma equivalente, por "no personal" de la última línea, "leyendo una novela", con la cual se llega al final del texto escrito y a la definitiva instauración de la circularidad. El espejismo de las palabras (uso este vocablo, "espejismo", en más de un sentido) ha anulado, o poco menos, la sensación del fluir temporal.

3. La estructuraciōn del relato. La estructuración de las acciones del relato presenta, por una parte, la particularidad de la división en dos párrafos de desigual extensión, ya mencionada: una ruptura o corte que sería preciso explicar; por la otra, un peculiar juego aspectual en los tiempos verbales, que es preciso aprehender para que la estructura de superficie de la narración comience a cobrar sentido en función de su estructura profunda. Conviene quizá comenzar por este último punto.

De acuerdo con la teoría gramatical moderna, (11) el aspecto es una de las modificaciones primarias --es decir, obligatorias-- en el componente llamado "auxiliar" del sintagma verbal; y las posibilidades del aspecto son dos, a saber, perfectivo o imperfectivo. En los tiempos del pasado, que es donde el contraste se puede establecer plenamente, el contrapunto de pretéritos ("volvió al libro", "se puso a leer los últimos capítulos"...) y de imperfectos ("se dejaba interesar lentamente por la trama", "gozaba del placer casi perverso"...) opone --como es habitual y natural en la lengua-- las acciones puntuales, in- 
dispensables para el conocimiento de la secuencia cronológica, a las durativas, que transmiten hechos concomitantes o estados de conciencia. Esto se reproduce fielmente, en el plano de las proposiciones principales, a lo largo de aproximadamente la primera mitad del primer párrafo cie "Continuidad de los parques". Pero en el trozo que va desde la línea 23 hasta la 40 --final del párrafo-- hay un cambio brusco: "Primero llegaba la mujer, recelosa; ahora llegaba el amante...", y de ahî hasta "empezaba a anochecer". Las formas verbales que en abrumadora mayoría comienzan a aparecer son imperfectivas, con olvido ya del habitual contrapunto: ¿por qué?

Es relativamente fácil contestar. Esa secuencia de formas imperfectivas --una 12 ó 15 -- está anclada en un perfectivo inmediatamente anterior: "fue" testigo del último encuentro en la cabaña del monte". Y entonces reconocemos el esquema: el nuevo esquema, aunque también íntimamente arraigado en las costumbres de la lengua.

Los niños, cuando juegan, traspasan al dominio del imperfecto, es decir, del tiempo más característicamente imperfectivo, la acción ficticia que tiene como marco el hecho mismo de jugar ("Tú/vos eras el ladrón y yo venía y te llevaba preso", por ejemplo). Anâlogamente, y lo que es más importante: cuando referimos un sueño, expresamos con el pretérito el hecho del soñar; con el imperfecto, el contenido de ese sueño. La forma canónica es, por ejemplo, "Soñé que estaba en un lugar maravilloso"; nunca *"Soñaba que estuve en un lugar maravilloso". De la misma manera se resuelve el problema en la literatura; por ejemplo, Antonio Machado en los "Proverbios y cantares" incluidos en Campos de Castilla (1917): (12)

Ayer soñe que veía

a Dios y que a Dios hablaba;

y soñé que Dios me oía...

Después soñé que soñaba.

¿Hace falta más glosa gramatical? Machado escribe "soñē" porque con esa forma expresa algo que se percibe como efectivamente acaecido, el acto mismo del soñar; escribe "veía" y "hablaba" porque tales formas verbales imperfectivas, cuando están enmarcadas por el perfecto o terminativo, denotan el territorio de la acción ficticia o no verificable; aquello que queda enmarcado una vez que se ha interrumpido --por el juego, por el sueño, por el avance de la imaginación que todo lo contamina-- el discurso exclusivamente racional.

Esto es precisamente lo que ocurre en el cuento de Cortá- 
zar: la acción marcada deliberadamente como "acción ficticia" está identificada mediante el uso exclusivo del imperfectivo (o imperfecto, o no terminativo). El personaje lector (es decir, el lector interno) ha entrado en la novela; el narrador refiere --sabiendo que se trata de una acción ficticia-- lo que ese lector ve. La extensión de tal "acción ficticia" o "referida", aquella que dentro del cuento se presenta -todavía-- como limitada a las páginas de la novela leída, es muy explícita: va desde "Primero entraba la mujer" (1. 24) a "Empezaba a anochecer" (1. 40). Y entonces se produce la pausa.

La pausa, el quiebre del fluir de la narración, el nuevo párrafo (aquí vuelve a ser importante, para el análisis, la repetidamente citada configuración o división del cuento en dos párrafos) no es un hecho casual. Está en relación con el cambio de estructura verbal subyacente, manifestado por un súbito desplazamiento al ámbito del pretérito. Es decir: desplazamiento al tiempo que sirve para caracterizar la acción como "efectivamente ocurrida" y no como "acción ficticia"; así, "se separaron en la puerta de la cabaña" (1. 42), "se volvió un instante para verla correr" (1. 44), "corrió a su vez" (1. 45). La acción relatada o inserta está cobrando autonomía: ningún signo verbal indica que se trate de una ficción segunda. Pero aún falta una última vuelta de tuerca. Hacia el final del cuento, cuando los dos planos ficcionales manejados hasta aquí se funden definitivamente en una "continuidad" manifiesta, llega a desaparecer hasta la oposición entre formas perfectivas e imperfectivas, puesto que se anulan --en favor de estructuras nominales-- todas las formas verbales propiamente dichas: sólo resuenan

las palabras de la mujer: primero una sala azul, después una galería, una escalera alfombrada. En lo alto, dos puertas. Nadie en la primera habitación, nadie en la segunda. La puerta del salón, y entonces el puñal en la mano, la luz de los ventanales, el alto respaldo de un sillón de terciopelo verde, la cabeza del hombre en el sillón leyendo una novela. (11. 51-57).

Ninguna forma verbal conjugada, como acaba de apreciarse: el mínimo de predicación, excepto la aseveración única de ser: la afirmación de que aquello que había sido presentado como el plano de la "acción ficticia" se ha confundido ahora, definitivamente, con el plano de la "acción real".

Teniendo en cuenta todas estas modulaciones, en consecuencia, el breve territorio del cuento aparecería dividido en cuatro sectores: a) el de una escritura "normal" o "convencional", caracterizada por la oposición --sistemática en la lengua-- 
entre los tiempos verbales que llamamos "pretérito" e "imperfecto" ("volvió a abrirla", "se dejaba interesar"); b) el de una un acción "ficticia", claramente marcada como ficción segunda, que se manifiesta en la forma habitual de transferencia de toda accion irreal al dominio del imperfecto ("Primero entraba la mujer, recelosa..."); c) el de un claro predominio --absorbente y enérgico-- del pretérito, mediante el cual se pone de relieve el avance de la ficción segunda sobre la ficción primera ("se separaron en la puerta de la cabaña..."); y d) el tramo final, de eliminación o elisión de las formas verbales (o personales) en su conjunto, que sanciona la mancomunión o fusión definitiva de los dos planos ficcionales. Nada hay, pues, de casual en el sutil ensamblaje de las formas verbales $--y$ de su ausencia-- a lo largo de estas apretadas 57 líneas de texto.

Anoto, para quien quiera proseguir el trabajo, que un análisis lingüístico más detenido de esta composición debería también prestar atención a por lo menos dos aspectos más: las abundantes formas deícticas, y las manifestaciones del elemento "adverbial" del sintagma verbal, sobre todo en su subcategorización "circunstancial de tiempo". Pero el examen de tales pormenores, que pudiera quedar para un estudio más detallado, no haría variar sustancialmente, en mi opinión, lo analizado hasta aquí.

Resumimos. El examen de "Continuidad de los parques" (Final del juego, 1964), de Julio Cortázar, permite observar que, sea o no correcta su inclusión en la categoría de "juego", aparece como testimonio de un avanzado proceso de literaturización, es decir, de atracción de la atención del lector hacia la forma de presentación, la estructura del contar. Se trata de una breve narración enmarcada, que juega con la idea de la transformación o pasaje de uno al otro de los dos planos, igualmente ficticios, que la constituyen. Ello se logra, fundamentalment, mediante tres estratagemas narrativas: la discreta utilización de un subtexto literario (una novela de D.H. Lawrence); una disposición de los elementos léxicos que subraya a la vez la ambigüedad de los significantes y la circularidad de la construcción; y la estructuración del relato no sólo segán las fases de la acción (como ocurriría en un discurso mimético o "realista"), sino sobre todo en términos de la estructura profunda, tal como ésta es manifestada por las configuraciones de tiempos verbales que ocupan la superficie del texto. Llega así éste --el texto-- a "decir", por procedimientos de los cuales el lector no alcanza precisa y puntual noticia, no solo to que Cortázar le permite que muestre, sino también todo aquello que el lenguaje mismo, y la tradición literaria de que es vehículo, no 
pueden sino revelar en los mejores ejemplos de escritura contemporánea. El mérito de Cortázar consiste en haber cifrado en este breve relato tantos elementos significativos: en abrir sus líneas para que sean canales de comunicación entre el texto presente y (potencialmente) numerosos textos ausentes; en suma, para que --como insinuamos al principio-- la temática "continuidad de los parques" sea la puerta para una auténtica (y subtemática, es decir, apoyada en la respuesta lectoral) "continuidad de la escritura". 


\section{NOTAS}

(1) Buenos Aires, Editorial Sudamericana, 1964. Es la edición que usamos.

( 2) Buenos Aires, Editorial Sudamericana, 1970.

(3) En su: En busca del unicornio: los cuentos de Julio Cortázar, Madrid, Gredos, 1983.

(4) Cf. mi trabajo "Rasgos distintivos de algunos cuentos de Julio Cortázar", Hispamérica, No 1 (1972), 5-15.

(5) Loc. cit.

(6) Op. cit., p. 242.

( 7) "Rasgos distintivos...", p.11-12.

( 8) Recordemos que "Pasajes" es una de las secciones de la compilación reordenada de los cuatro primeros libros de cuentos de Cortázar, Relatos, ya citada.

( 9) Cf. el ensayo de Hugo J. Verani, "Shahrazad o la perfección de la mentira", Letras de Buenos Aires, III, 10 (1983), 41-51.

(10) D. H. Lawrence, Lady Chatterley's Lover, New York, New American Library, c. 1959, 1962.

(11) Robert P. Stockwell, J. Donald Bowen, John W. Martin, The Grammatical Structures of English and Spanish, Chicago, The University of Chicago Press, 1965; vease especialmente el cap. 6, "The Auxiliary Constituents of the Ver Phrase". Sobre el aspecto verbal en general puede consultarse el más reciente libro de Bernard Comrie, Aspect, Cambridge, Cambridge University Press, 1976.

(12) Cito por la siguiente edición: Antonio Machado, Poesías, 6a. ed., Buenos Aires, Editorial Losada, 1965, p. 163. 